\title{
Concepção de partido em Rosa Luxemburg
}

Renato César*

Resumo

O objetivo do presente artigo é demonstrar a existência de uma concepção de partido na obra de Rosa Luxemburg e mostrar a relação que a autora estabelece entre o partido político socialista (e o proletariado como parte do mesmo) e sua direção política.

PalaVras-chaVe: Rosa LuXemburg, PARTido Político, MARXismo, VANGUARda

\section{Abstract}

The present article aims to demonstrate the existence of a party conception in Rosa Luxemburg's work and to show the relation that she establishes between the socialist political party (and the proletariat as part of itself) and its political direction.

Keywords: Rosa Luxemburg, political party, Marxism, vanguard.

No presente artigo, trataremos do pensamento de Rosa Luxemburg sobre a questão do partido. A hipótese aqui desenvolvida é que a autora polonesa tem um "esboço"

*Graduando em Ciências Sociais no Instituto de Filosofia e Ciências Humanas da Universidade Estadual de Campinas. Membro do grupo de Pesquisa Marxismo e Teoria Política, sediado no Centro de Estudos Marxistas da Unicamp (Cemarx/Unicamp). Este artigo sintetiza resultados de pesquisa de Iniciação Científica financiada pelo Programa Institucional de Bolsas de Iniciação Científica (Pibic/CNPq-PRP/Unicamp).

cadernos cemarx, no $4-2007 \quad 55$ 
não sistemático e não articulado sobre a questão da organização, o qual mantém uma coerência com todo o seu pensamento, o que permite dizer, então, que ela não tem uma teoria do partido, mas uma concepção de partido.

O presente trabalho está inscrito no conjunto de reflexões feitas no Brasil, e em outros países sobre o pensamento de Rosa Luxemburg, que procura buscar através da sua própria obra as contradições, limitações e inovações das quais era portadora, no sentido de reconstruir a reflexão da autora, superando as leituras superficiais e marcadas por pré-noções que caracterizaram a produção precedente.

Por essas razões, este artigo estabelece um diálogo e utiliza como base a pesquisa de Isabel Loureiro (2004), autora de grande importância no estudo de Rosa Luxemburg, que demonstra a tensão permanente do pensamento da autora polonesa: a contradição entre o objetivo socialista do partido operário e a prática reformista da classe operária, o que a levou a uma teoria da e para a práxis. Esta contradição permanente em seu pensamento só pode ser entendida na relação histórico-crítica com o momento dos seus escritos e a finalidade política destes: seja combatendo a burocratização no SPD (Partido Social-democrata Alemão) ou nos sindicatos, seja combatendo o nacionalismo do PPS (Partido socialista polonês) ou ainda defendendo a democracia operária na Revolução Russa.

A relação entre o tempo da análise e o tempo da política é fundamental para podermos apontar na concepção de partido de Rosa Luxemburg uma síntese entre os momentos de espontaneidade e de consciência, procurando estabelecer em cada situação concreta qual é o principal fator da ação de classe. Neste sentido, a concepção de partido de Rosa Luxemburg não é uma receita pronta ou uma fórmula mágica para solucionar o problema da luta da classe operária, mas uma compreensão do movimento real da classe e da sociedade capitalista.

\section{LUTA DE ClASSES: O FAZER-SE DO PARTIDO E DA CLASSE}

Para Rosa Luxemburg, o partido proletário é resultado da luta de classes entre a burguesia e o proletariado: é no processo da luta de classes que se põe a necessidade da existência de um organismo político para o desenvolvimento do combate proletário - essa necessidade não se dá somente nos grandes acontecimentos da lutas de classes, como as revoluções, mas mesmo nas lutas de classe mais elementares, isto é, nas lutas mais imediatas, como as reivindicações salariais ou redução da jornada de trabalho.

56 Concepção de partido em Rosa Luxemburg 
O partido político para a marxista polonesa aparece como um dos fatores da luta de classe, dentre outros, sendo um fator importante que cumpre o papel de vanguarda e direção política do movimento de massas da social-democracia, necessário para a superação de um estado da luta de classes, colocando em questão o poder político estatal. Para concretizar este papel, segundo Luxemburg, o partido político deve realizar três funções:

- Organizar a classe operária: o partido é necessário para organizar a classe nos organismos de resistência econômica ou política, de forma a buscar uma coesão para a classe na sua luta, superando sua fragmentação e dispersão;

- Esclarecer (Aufklärer) a classe operária: o partido político por sua própria posição na luta de classes é quem pode dar uma visão geral da luta de classes, isto é, desenvolver uma teoria e uma estratégia para a luta da mesma através da análise histórica e de sua tradução em um programa político. É o partido que consegue sintetizar a política necessária na relação entre as necessidades imediatas e as necessidades históricas da classe operária, mas é somente a classe que consegue transformá-la em ação;

- Instigar a luta da classe operária: o partido deve indicar e defender uma política socialista no movimento operário; deve levar o programa estabelecido através da sua análise da luta de classes, da história e da economia capitalista, para o seio da classe operária, impulsionando suas lutas; esta materialização é sempre uma relação dialética entre a ação de massas e do partido político, e não de um dos dois separadamente.

Estas três funções definem em linhas gerais a concepção de Rosa Luxemburg sobre o partido político. $O$ papel do partido não pode ser compreendido sem a compreensão da historicidade do antagonismo social e suas funções não podem ser entendidas como formas separadas do processo de luta de classes: o tempo e a intensidade de cada uma das atividades varia de acordo com o desenrolar do processo histórico e da luta de classes. Para Luxemburg,

a social-democracia (...) nasce historicamente da luta de classes elementar. E move-se na contradição dialética de que só na própria luta é recrutado o exército do proletariado e de que também, só na luta, as tarefas da luta se tornam claras. Organização, esclarecimento e luta não são aqui momentos separados, mecanicamente e temporalmente distintos, como num movimento blanquista, mas são apenas diferentes aspectos do mesmo processo. (...) o

cadernos cemarx, no $4-2007 \quad 57$ 
processo de luta que cria a organização conduz a uma constante flutuação da esfera de influência da social-democracia. $(1991: 43)^{1}$

A compreensão de que o partido nasce da luta de classes e que depende dela para desenvolver suas funções foi conceituada como partido-processo, isto é, o partido é parte do processo histórico e se transforma com ele, o que é coerente com a compreensão de Rosa Luxemburg. O objetivo dessa compreensão é demonstrar que o partido não é o fator principal e não substitui a ação de massas, mas também não é um fator irrelevante. Pelo contrário, a luta de classes ocorre independente da existência do partido, mas a classe operária só conseguirá superar sua própria condição no capitalismo colocando a questão da tomada do poder político através do partido. $\mathrm{O}$ partido-processo, para autora polonesa, está relacionado com a contradição permanente no seu pensamento entre os momentos subjetivos e objetivos: a formação das condições objetivas deve resultar a constituição das condições subjetivas; neste sentido, não há uma classe operária pronta ou um partido monolítico, mas estes se realizam no seu próprio fazer-se (Thompson, 1987) em determinadas condições objetivas. Para Rosa Luxemburg, "o inconsciente precede o consciente, a lógica do processo histórico objetivo precede a lógica subjetiva dos seus portadores" (1991: 47), mas a ação subjetiva possibilita transformações objetivas em uma contínua dialética. Não é somente a classe operária que se faz na luta cotidiana, mas o partido (que é parte da classe) também se faz na luta de classes, desenvolvendo em conjunto com a sua luta a sua própria compreensão da mesma. A importância da luta sindical e política deve-se não só à preparação dos fatores subjetivos, mas também a formação dos fatores objetivos para a superação do capitalismo (Luxemburg, 2003: 59-60. Cf. Frölich, 1976; Basso, 1976 e Geras, 1978).

\section{A CONTRADIÇÃo FUNDAMENTAL DO MOVIMENTO SOCIAL-DEMOCRATA}

Como superar a sociedade burguesa sendo obrigada a lutar dentro desta sociedade? Esta contradição é abordada e explanada diversas vezes na obra de Rosa Luxemburg e coloca-se como um ponto determinante no entendimento dos fatores da luta de classes:

1 Rosa Luxemburg utiliza-se dos termo social-democracia e partido social-democrata como sinônimos.

58 Concepção de partido em Rosa Luxemburg 
“Toda a particularidade desse movimento reside precisamente no fato de deverem as massas populares, pela primeira vez na história e contra todas as classes dominantes, impor uma vontade própria que só irão realizar passando por cima da sociedade atual, saindo dela. Mas, por sua vez, só podem as massas formar esta vontade numa luta constante contra a ordem existente, nos quadros desta." (2003: 116)

Para Rosa Luxemburg, o partido proletário é concebido como parte da classe operária, assumindo um papel específico no movimento operário: de dirigir o movimento através da organização, do esclarecimento e da indução a luta da classe operária contra a burguesia. Neste sentido, o partido é parte do processo histórico da luta de classes e não está separado ou fora da classe operária (como compreendia Kautsky): "a social-democracia não está ligada à organização da classe operária, ela é o próprio movimento da classe operária” (Luxemburg, 1991: 44).

Diferentemente dos sindicatos, que só representam a luta econômica dos proletários de forma parcial e em uma etapa circunscrita do movimento, a social-democracia "representa a classe operária e a causa de sua libertação como totalidade" (Luxemburg, 2005: 322): a luta do partido é a luta pelo poder político.

É na relação entre a luta política e a luta econômica, que envolve o partido, os sindicatos e as massas, que se abre a possibilidade da universalização da luta da classe operária, a possibilidade de contrapor a sociedade socialista à sociedade burguesa. Esta tarefa se realiza na ação da social-democracia, que é o único elemento capaz de universalizar a luta de classes em todas as esferas: econômica, política e teórica, porque a social-democracia luta pelo poder político, isto é, pelo controle do Estado, mas não de forma parcial, como anunciavam os revisionistas, mas de forma total, com a intenção de colocar "a totalidade do poder político" (Luxemburg, 2004a: 298) nas mãos da classe operária.

É importante ressaltar que, para Rosa Luxemburg, a totalidade do poder político só poderá ser conquistada em conjunto com o controle da produção nas fábricas, que é a base para a ditadura do proletariado, isto é, apenas em um "autogoverno dos trabalhadores no plano político e econômico" (Loureiro, 2004: 231). Dessa forma, a tomada do poder político só pode ser uma tomada pela base e não pelo alto (Luxemburg, 2004b: 344). Esta universalização da luta é fundamental para a oposição da política socialista à política capitalista, a qual, para a autora, deve se manifestar em todos os momentos. Isto é, a política social-democrata não deve se contentar com 
a crítica da política burguesa "mas opor-lhe, taco a taco, o projeto duma sociedade socialista que ultrapassará a política burguesa mais avançada" (1979: 36).

Para concretizar esta oposição, a social-democracia deve inserir a perspectiva socialista em todas as lutas concretas da classe operária, isto é, deve realizá-las a partir do ponto de vista de classe, da conquista do poder, da transformação social e não somente através das lutas democráticas ou pela democracia representativa. A luta pela democracia deve ser visualizada como parte da luta pelo socialismo, na luta da classe operária pelo poder político. Segundo Luxemburg,

Divide-se a luta prática propriamente dita em três partes principais: luta sindical, luta pelas reformas e luta pela democratização do Estado capitalista. São essas três formas de nossa luta, de fato, socialismo? Absolutamente não! (...) O que é então que faz de nós, em nossa luta cotidiana, um partido socialista? Só e unicamente a relação entre essas três formas de luta prática e o nosso objetivo final. Somente a finalidade dá à nossa luta socialista espírito e conteúdo, e faz dela uma luta de classe. E não devemos compreender por finalidade, como o disse Heine, tal ou qual representação da sociedade futura, e sim o que deve preceder a qualquer sociedade futura, isto é, a conquista do poder político. (1975: 96-97)

A superação da contradição entre a luta imediata e o objetivo final, para Rosa Luxemburg, é fundamental e só poderá ser feita na unidade entre a classe operária, através da sua "ação audaz" e da orientação e direção política do partido social-democrata: somente com a luta pelo poder político e pelo socialismo que será possível superar a contradição do movimento social-democrata.

\section{O MOMENTO DA DIREÇÃo E A BASE SOCIAL DO PARTIDO SOCIAL-DEMOCRATA}

O partido como vanguarda que faz parte da classe operária ganha potencialidade nas situações revolucionárias, nas quais as contradições do capitalismo afloram de forma abrupta e violenta e é colocada no processo a questão da tomada do poder político. Na discussão sobre a greve de massas, Rosa Luxemburg compreendeu que o partido não tem a função de preparar ou organizar a greve em si, mas de:

assumir a direção política da greve no período revolucionário (...). Proporcionar linha e direção à luta; adaptar as táticas a serem utilizadas em cada fase e em cada momento da luta

60 Concepção de partido em Rosa Luxemburg 
política de tal modo que toda a força disponível do proletariado, já sublevado e ativo, encontre expressão no plano de batalha do partido; cuidar para que as táticas a serem aplicadas pelos social-democratas sejam decididas e inteligentes e que nunca fiquem abaixo do nível exigido pela real relação de forças, mas, sim que superem esse nível; essa é a tarefa mais importante da organização dirigente em uma etapa de greve de massas. Essa direção vai se transformado, de certo modo, em direção especializada. Uma tática coerente, decidida, que evolua progressivamente, empregada pelos social-democratas, produz nas massas um sentimento de segurança, de confiança em si mesmos e desejo de lutar; uma tática vacilante, fraca, baseada na subestimação do proletariado paralisa e confunde as massas. (2005, p. 294)

A ação contínua e correta da vanguarda partidária prepara os "sentimentos morais" das massas, as tornam mais confiantes para o enfrentamento da luta de classes. A direção política do partido não está garantida por um comando arbitrário ou por uma substituição do fazer das massas operárias, mas numa elaboração, agitação, organização e luta para adaptar-se à situação, buscando transformar sempre a ação de massas imediatas em luta pelo objetivo final socialista, não deixando perder o vínculo entre ambas (Loureiro, 1994: 25), procurando sempre uma política que não se reduza à minoria organizada, mas à ampla massa do proletariado. Para Luxemburg,

Se os social-democratas, enquanto núcleo organizado da classe operária, são a vanguarda mais importante do conjunto dos operários, e se a clareza política, a força e a unidade do movimento operário surgem de tal organização, não se pode conceber a mobilização de classes do proletariado como mobilização da minoria organizada. Toda grande luta de classes deve se basear no apoio e na colaboração das mais amplas massas. Uma estratégia para a luta de classes que não conte com esse apoio, que tenha por base uma manifestação realizada por um pequeno setor bem capacitado do proletariado, está destinada a terminar em um miserável fracasso. (2005: 306-307)

Neste ponto se coloca uma importante discussão para a compreensão do partido em Rosa Luxemburg: qual é a base social do partido social-democrata? Para a autora polonesa, a base da social-democracia não é apenas o operariado urbano e rural, mas também a pequena-burguesia e os pequenos camponeses, que devem se submeter a política operária, que é a única capaz de superar o capital (cf. Basso, 1976: 134-135). A definição da base social da social-democracia como o proletariado (operários 
assalariados e as classes com duplo caráter econômico) é fundamental para entendermos sua polêmica com Lenin a respeito do combate ao revisionismo: para Rosa Luxemburg, o revisionismo era a expressão das classes intermediárias (com duplo caráter econômico) no movimento social-democrata e não algo externo ao próprio movimento. Visto que o movimento social-democrata deveria reunir sob sua bandeira todos os setores do proletariado, esta é uma contradição interna ao movimento socialista, com a qual o próprio movimento deve lutar para sua superação. Para Rosa Luxemburg a social-democracia deve assumir o papel de vanguarda do movimento operário em todos os momentos, mas em cada temporalidade a sua potencialidade será diversamente limitada, podendo a ação espontânea ou o momento de direção ser mais importante de acordo com a situação história. A política da social-democracia, em todos os momentos, deve saber opor-se à totalidade da política capitalista e não apenas parcialmente, como defendiam os revisionistas.

No processo de desenvolvimento da luta de classes há momentos de lutas pequenas (salário, melhorias nos bairros...) e de grandes lutas (tomada das fábricas, luta pelo poder político...); de lutas parciais aparentemente parciais e de lutas que conseguem opor claramente a política socialista a política capitalista. Para Rosa Luxemburg, o partido social-democrata não pode ter uma política limitada a cada luta em si, mas saber vincular a luta elementar à luta socialista; mas ao mesmo tempo, o partido não deve desprezar a luta por ela mesma e deve partir das lutas elementares para a luta socialista. Esta vinculação da luta elementar-luta socialista é a forma como o movimento operário pode buscar realizar a superação da sua própria contradição: uma

política que se limite a luta em si é reformista, enquanto uma política que não parta da luta em si, é sectária. (Luxemburg, 1977: 151 e 1974: 149).

O partido como direção política, capaz de universalizar a luta do proletariado, aparecendo como vanguarda na totalidade do processo histórico e como parte constituinte do movimento proletário é, para Luxemburg, o único capaz de realizar a autodeterminação do proletariado, isto é, o único com a possibilidade de formar uma vontade coletiva que faça a classe operária superar a burguesia e o capitalismo.

\section{AUTODETERMINAÇÃo, EXPERIÊNCIA E ESPONTANEIDADE}

O partido para Rosa Luxemburg não se apresenta como a "consciência socialista" ou como a realização da forma de vida socialista. Pelo contrário, o partido é o

62 Concepção de partido em Rosa Luxemburg 
organismo capaz de preparar, esclarecer a classe operária na própria luta contra a burguesia, sendo parte do próprio movimento socialista. Mas qual é o objetivo da luta do partido do proletariado?

A social-democracia é o partido classista do proletariado. Seu objetivo histórico é ser o porta-voz dos interesses do proletariado e, ao mesmo tempo, dos interesses do desenvolvimento revolucionário da sociedade capitalista em sua marcha para a realização do socialismo. Portanto, a social-democracia tem a missão de tornar possível não o direito dos povos à autodeterminação, mas o direito da classe operária, da classe explorada $\mathrm{e}$ perseguida, o proletariado, à autodeterminação. (Luxemburg, 1988: 43-44)

É somente no processo histórico da luta de classes que o proletariado e sua vanguarda podem desenvolver a consciência de superação da sua condição: é somente na experiência da luta de classes que poderá ser desenvolvido o programa político e a forma de superação da sociedade burguesa. A teoria, a propaganda e a organização entram somente como meios importantes, mas não centrais para a formação da consciência de classe, sendo o principal meio a luta, a ação audaz, a "vida", o fazer-se da classe operária e, por conseqüência, do seu partido:

O proletariado não pode reunir as suas tropas e aumentar as suas forças, com vista à vitória final, senão na própria experiência da luta. Deve aceitar as derrotas e as alternativas que um combate deste tipo implica. Uma grande luta - quer termine com uma vitória ou uma derrota - traz consigo mais progressos, quanto à lucidez e à experiência históricas, do que milhares de brochuras de propaganda ou milhares de reuniões em período de calma (Luxemburg, 1977: 161).

Na luta, não há receitas prontas ou modelos mecânicos aos quais a social-democracia deveria adaptar-se ou de acordo com os quais deveria dirigir o proletariado, com a intenção de fazer avançar a luta de classes. Cada desenvolvimento da luta operária aparece como um desenvolvimento particular e específico, dentro de uma totalidade, que deve ser teorizado e compreendido para que o partido possa dirigir a classe operária. A política do partido deve ser de impulsionar, instigar, levando até as últimas conseqüências a luta operária nas condições dadas.

Destacando a autodeterminação da experiência da luta operária, podemos

cadernos cemarx, no $4-2007 \mid 63$ 
concordar com Frölich (1976), o qual defende a não existência de uma teoria da espontaneidade na obra de Rosa Luxemburg, mas sim uma elaboração e tentativa de compreensão do momento "espontâneo" da luta de classes. O "espontâneo" é o momento no qual, na luta de classes, o proletariado dá respostas diferenciadas e não organizadas à própria luta, sendo estas respostas inerentes (o que não quer dizer "naturais") ao desenvolvimento do ser social e da sua luta. Esta resposta terá como base, em sua maior parte das vezes, a própria experiência imediata dos operários: na fábrica, no lar ou nos seus momentos de convivência. A este momento espontâneo, Rosa Luxemburg tentará articular o momento da direção, o momento da organização política. Diferentemente de Guérin (1982) e Varcárcel (1975), que afirmam a inexistência de uma síntese teórica entre os dois momentos na obra de Rosa Luxemburg, acreditamos que a autora polonesa buscou a síntese, principalmente durante a Revolução Alemã, entre a ação da vanguarda (Liga Spartakus e o Partido Comunista Alemão, KPD) e a espontaneidade das massas, que não apontavam para além da política do SPD (Loureiro, 2004: 236-237), não conseguindo realizá-la.

A tentativa de síntese pode ser percebida tanto na defesa que Rosa Luxemburg faz da tomada do poder pelos conselhos, quanto da participação na Assembléia Constituinte (Luxemburg, 2004b). No momento em que Rosa Luxemburg escreveu, sabia que a tomada do poder pelo KPD não era uma alternativa para as massas: a classe buscava a união entre o SPD, o KPD e USPD (Partido social-democrata independente), visto que por mais de 40 anos, o partido do proletariado tinha sido o SPD, então partido governante na Alemanha.

A síntese entre o elemento espontâneo das massas operárias e o elemento dirigente do partido operário, composição esta que vai depender das condições materiais da luta de classes, pode ser percebida no papel desempenhado pela relação entre os mesmos: a função de dirigente não pode ser parasitária, tem que estabelecer um fluxo contínuo entre o elemento dirigente e a consciência da experiência das massas, lembrando que o momento do espontâneo não pode ser eterno e que deve ser transformado. Por isso,

O único papel dos pretendidos 'dirigentes' da social-democracia consiste em esclarecer a massa sobre sua missão histórica. (...) o seu prestígio e a sua influência só aumentam na medida em que os seus chefes destruam aquilo que até aqui foi a base de toda a função dos dirigentes: a cegueira da massa, na medida em que se despojam

64 Concepção de partido em Rosa Luxemburg 
a si próprios da sua qualidade de chefes, na medida em que façam da massa a efetiva entidade dirigente, e de si próprios os órgãos executivos da ação consciente da massa. (Luxemburg, 1972: 87)

Para Rosa Luxemburg uma das funções do partido é transformar as próprias massas de dirigidas em dirigentes do processo histórico e para isso é preciso uma política socialista, de esclarecimento, organização e luta: as massas podem superar sua condição de classe somente quando elas próprias assumirem o controle do processo histórico, principalmente, através dos conselhos operários que apareceram como concretização da ação das massas nas revoluções do pós-guerra.

Com isto, ao contrário de Stalin (1975) e Bensäid e Nair (1969), que afirmam que a concepção de Rosa Luxemburg era espontaneísta e desprezava o elemento de direção, acreditamos que não há este desprezo na obra da autora, mas uma tentativa de uma síntese, através da compreensão do momento histórico e da experiência da luta da classe operária.

\section{Centralismo enQuANTo PROBlema histórico}

Os problemas que Rosa Luxemburg levantou e discutiu em sua obra foram analisados pela dupla ótica do materialismo histórico: análise histórica do desenvolvimento social e análise econômica da sociedade. A questão da organização não é diferente.

Na sua polêmica com Lenin sobre a social-democracia russa, Rosa Luxemburg afirma: "em nenhum campo a concepção marxista do socialismo se deixa imobilizar em fórmulas rígidas, nem mesmo na questão da organização" (1991: 40). Para a autora polonesa não existe uma fórmula ou um modelo para a organização e é por isso que o problema do centralismo é uma questão histórica: Rosa Luxemburg não era contra todo o tipo de centralismo, ao contrário, ela acreditava que o próprio movimento social-democrata deveria ser centralizado para conseguir responder ao sistema capitalista altamente centralizado:

Esta tendência centralista do desenvolvimento do capitalismo representa uma das bases principais do futuro regime socialista, pois somente a máxima concentração da produção e da troca permite estabelecer uma economia socialista planificada em escala mundial. Por outra parte, só mediante a concentração e a centralização, tanto da classe 
operária como força de combate como também do poder estatal, torna-se possível que o proletariado tome finalmente este poder em suas mãos para estabelecer sua ditadura e levar a cabo a revolução socialista. (Luxemburg, 1988: 84)

Mas o centralismo da social-democracia deveria ser totalmente diferente do movimento blanquista: o centralismo social-democrata deve ser um "autocentralismo", isto é, ele deve partir diretamente da experiência de luta prática das massas para elaboração de uma resposta pela direção partidária - como já fizemos referência, o partido é um formador da autodeterminação proletária, mas não é a mesma.

O centralismo social-democrático precisa, pois, ser de natureza essencialmente diferente do centralismo blanquista. Ele só pode ser a concentração imperiosa da vontade da vanguarda esclarecida e militante do operariado perante seus diferentes grupos e indivíduos. É, por assim dizer, um 'autocentralismo' da camada dirigente do proletariado, é o domínio da minoria no interior da sua própria organização partidária. (Luxemburg, 1991: 44)

O autocentralismo não é nada mais do que fazer com que não haja uma separação rígida entre a direção e a base partidária, entre o partido e a classe operária: o autocentralismo é aquele onde os militantes aceitam "o domínio da minoria" por concordarem com ele e não porque lhes és imposta a política.

É por considerar a experiência um elemento fundamental da teoria e estratégia social-democrata que Rosa Luxemburg vai priorizar a luta das massas à luta entre partidos; não desprezando esta, mas colocando que somente através da sua própria luta é que as massas operárias vão poder ter clareza dos seus objetivos. Tal clareza seria não um resultado natural ou mecânico, mas o produto das ações dos mediadores, como o partido, no processo histórico. A temporalidade predominante da luta de massas faz com que o centralismo só possa ser efetivo se for como resposta direta a esta luta de massas e não apenas a dimensão partidária.

Em sua polêmica sobre a organização da social-democracia russa, mesmo considerando a necessidade da direção do partido, Rosa Luxemburg afirma que:

O papel da direção social-democrática é, portanto, de caráter essencialmente conservador, como o demonstra a experiência: cada vez que um novo terreno de luta é

66 Concepção de partido em Rosa Luxemburg 
conquistado e levado até as últimas conseqüências, é logo transformado num baluarte contra posteriores inovações em maior escala. (1991: 47)

Não seria esta uma demonstração de que Rosa Luxemburg desprezaria o momento da direção? Não, se entendermos o momento da análise e da política contida neste trecho: a crítica que Rosa Luxemburg faz não está somente direcionada ao debate com Lenin, mas à direção conservadora do SPD, que em momentos de avanço da luta proletária procurou barrá-la. Rosa Luxemburg é contrária a substituição das massas pelo partido e considera que a transformação das situações objetivas deve levar a uma transformação da política do partido, um fazer-se, para que o mesmo não se mantenha em uma fase anterior e por isso mesmo, conservadora do processo de luta de classes. É necessário, portanto, que haja uma relação contínua entre o partido e as massas operárias tanto para as massas ultrapassarem sua condição de classe, quanto para o partido não barrar o avanço da luta e isto só pode ser possível se compreendermos os diferentes tempos da luta de massas e da luta do partido.

\section{ConClusão}

A concepção de partido de Rosa Luxemburg, conforme tentamos demonstrar, apesar de levantar diversos elementos importantes para uma teoria do partido operário (base social, funções, relação com a classe social, caráter do revisionismo, centralismo, espontaneidade...), apesar de coesa, deixa-nos sem uma elaboração sistemática sobre as formas que o partido assume em cada momento histórico ou em um momento histórico, sobre a definição mais aprofundada das funções e atividades do partido operário.

Apesar de não ter uma teoria elaborada sobre a questão do partido, que dentro da tradição marxista deve ser compreendida em conjunto com uma teoria da revolução, os elementos da reflexão de Rosa Luxemburg são importantes para uma análise dos partidos contemporâneos, ajudando-nos a compreender os caminhos seguidos por diversos partidos social-democratas e comunistas no pós-guerra, sem esquecer-se de uma análise do movimento real da classe e da sociedade.

A compreensão de Rosa Luxemburg sobre a questão do partido, dentro da sua polêmica com Lenin e com a social-democracia alemã, não pode ser entendida como um "tipo ideal" ou uma receita para um partido moderno, mas como uma análise 
das condições objetivas e subjetivas do próprio processo histórico na tentativa de compreender o fazer-se da formulação política do partido socialista.

A síntese que Rosa Luxemburg procurou em toda sua vida estabelecer entre o momento espontâneo e o momento da direção é importante para refletirmos sobre as deformações que lhe foram impostas e também para entendermos os processos históricos de organizações que atuaram na realidade brasileira, como o Partido Comunista Brasileiro e o Partido dos Trabalhadores.

68 Concepção de partido em Rosa Luxemburg 


\section{Bibliografia}

BASSO, Lelio. El pensamiento político de Rosa Luxemburg. Barcelona: Península, 1976.

BENSAID, D. e A. Nair. “A Propósito del Problema de Organizacion: Lenin y Rosa Luxemburgo”. In: VVAA. Teoria Marxista del Partido Político II. Córdoba: Pasado y Presente, 1969.

FRÖLICH, Paul. Rosa Luxemburg: vida y obra. Madrid: Fundamentos, 1976.

GERAS, Norman. A actualidade de Rosa Luxemburgo. Lisboa: Antídoto, 1978.

GUÉRIN, Daniel. Rosa Luxemburgo e a Espontaneidade Revolucionária. São Paulo: Perspectiva, 1982.

LENIN, Vladimir. Obras Escolhidas, vol I. São Paulo: Alfa e Omega, 1979.

LOUREIRO, Isabel. Rosa Luxemburg: os dilemas da ação revolucionária. São Paulo: Fundação Perseu Abramo, 2004.

“"Rosa Luxemburg e Trotski: a revolução russa de 1905”. In: Osvaldo Coggiola. (Org.). Trotski hoje. São Paulo: Ensaio, 1994, p. 21-34.

LOUREIRO, Isabel \& VIGEVANI, Túlio. (orgs.). Rosa Luxemburg: A Recusa da Alienação. São Paulo: UNESP, 1991.

LÖWY, Michael. Método Dialético e Teoria Política. Rio de Janeiro: Paz e Terra, 1975.

LUXEMBURG, Rosa. A Crise da Social-Democracia. Lisboa: Presença, 1974.

. A questão nacional e autonomia. Belo Horizonte: Oficina de Livros, 1988.

A Revolução Russa. Petrópolis: Vozes, 1991.

. Camarada e Amante: cartas de Rosa Luxemburgo a Leo Jogiches. Rio de Janeiro: Paz \& Terra, 1983.

. Introdução a economia política. São Paulo: Martins Fontes, 1977.

. O Estado Burguês e a Revolução. Lisboa: Antídoto, 1979.

. “Chefes e massas". In: VVAA. Rosa Luxemburgo, viva! (Antologia). Porto: editora do autor, 1972, p. 85-94.

. “Greve de massas, partidos e sindicatos”. In.: BOGO, Ademar (org.). Teoria da organização política I - escritos de Engels - Marx - Lenin - Rosa - Mao. São Paulo: Expressão Popular, 2005.

. Reforma ou Revolução? São Paulo: Expressão Popular, $3^{\text {a }}$ ed., 2003.

cadernos cemarx, nํ $4-2007 \quad 69$ 
. "Discurso sobre a tática”. In:. LUXEMBURG, Rosa. Reforma, revisionismo e oportunismo. Rio de Janeiro: Civilização Brasileira, 1975, p. 96-97.

. “O que quer a Liga Spartakus?”. In.: LOUREIRO, Isabel. Rosa Luxemburg: os dilemas da ação revolucionária. São Paulo: Fundação Perseu Abramo, 2004a, p.291-304.

. “Congresso de fundação do Partido Comunista Alemão”. In.: LOUREIRO,

Isabel. Rosa Luxemburg: os dilemas da ação revolucionária. São Paulo: Fundação Perseu Abramo, 2004b, p. 305-345.

. Textos Escolhidos. Lisboa: Estampa, 1977.

STALIN, J. Acerca das questões do leninismo. Lisboa: Ed. Estampa, 1975.

THOMPSON, E. P. A formação da classe operária inglesa. Rio de Janeiro: Paz e Terra, 1987.

VALCÁRCEL, José. La pasión revolucionária de Rosa Luxemburgo. Madrid: Akal, 1975.

70 Concepção de partido em Rosa Luxemburg 